are not clue wholly to sudden changes in the magnetic condition of the iron core, as heretofore supposed, but that a portion of the effect results from vibrations in the insulated copper wires composing the coils. An electro-magnet was arranged upon circuit unto an instrument for interrupting the current, the rheotome being placed in a distant room so as to avoid interference with the experiment. Upon applying the ear to the magnet a musical mas clearly perceived, and the sound continued after the iron core had been removed from the coils. The effect may probably be explained by the attraction of the coils for one another during the passage of the galvanic current and the sudden cessation of such attraction when the current ceased. It is probable, too, that a molecular vibration is occasioned in the conducting wire by the passage of an intermittent current. I have found that very distinct sounds proceed from straight pieces of iron, steel retort-carbon, and plumbago, when an intermittent current is passed through them."

When a powerful current is passed through the body a musical note can be perceived when the ear is closely applied to the arm of the person experimented upon. The sound seems to proceed from the muscles of the forearm and from the biceps muscle. Mr. Elisha. Gray has also produced audible effects by the passage of electricity through the human body. An extremely loud musical note is occasioned by the spark of a Ruhmkorff's coil when the primary circuit is made and broken with sufficient rapidity; when two rheotomes of different pitch are caused simultaneously to open and close the primary circuit a double tone proceeds from the spark.

A curious discovery has been made by Prof. Blake. He constructed a telephone in which a rod of soft iron, about six feet in length, was used instead of a permanent magnet. A friend sang a continuous musical tone into the mouth-piece of a telephone, which was connected with the soft iron instrument alluded to above. It was found that the loudness of the sound produced in this telephone varied with the direction in which the iron rod was held, and that the maximum effect was produced when the rod was in the position of the dipping needle.

This curious discovery of Prof. Blake has been verified by Prof. Bell.

"Prof. Peirce has observed the most curious sounds produced from a telephone in connection with a telegraph-wire during the aurora borealis; and I have just heard of a curious phenomenon lately observed by Dr. Channing. In the City of Providence, Rhode Island, there is an over-house wire about one mile in extent with a telephone at either end. On one occasion the sound of music and singing was faintly audible upon one of the telephones. It seemed as if some one were practising vocal music with a pianoforte accompaniment. The natural supposition was that experiments were being made with the telephone at the other end of the circuit, but upon inquiry this proved not to have been the case. Attention having thus been directed to the phenomenon, a watch was kept upon the instruments, and upon several subsequent occasions the same fact was observed at both ends of the line by Dr. Channing and his friends. It was proved that the sounds continued for about two hours, and usually commenced about the same time. A searching examination of the line disclosed nothing abnormal in its condition, and I am unable to give you any explanation of this curious phenomenon. Dr. Channing has, however, addressed a letter upon the subject to the editor of cne of the Providence papers, giving the names of such songs as were recognised, with full details of the observations, in the hope that publicity may lead to the discovery of the performer, and thus afford a solution of the mystery."

Prof. Bell referred to some experiments made by Mr. F. A. Gower and himself to show the slight earth connection required to establish a circuit for the telephone.
"One experiment which we made is so very interesting that I must speak of it in detail. Mr. Gower made earth connection at his end of the line by standing upon a grass plot, whilst at the other end of the line I stood upon a wooden board. I requested Mr. Gower to sing a continuous musical note, and to my surprise the sound was very distinctly audible from the telephone in my hand. Upon examining my feet I discovered that a single blade of grass was bent over the edge of the board, and that my foot touched it. The removal of this blade of grass was followed by the cessation of the sound from the telephone, and I found that the moment I touched with the toe of my boot a blade of grass or the petal of a daisy, the sound was again audible."

Prof. Bell concluded as follows :- "The question will naturally arise, through what length of wire can the telephone be used? In reply to this I may say that the maximum amount of resistance through which the undulatory current will pass, and yet retain sufficient force to produce an audible sound at the disturbed end, has yet to be determined; no difficulty has, however, been experienced in laboratory experiments in conversing through a resistance of $60,000 \mathrm{ohms}$, which has been the maximum at my disposal. On one occasion, not having a rheostat at hand, I may mention having passed the current through the bodies of sixteen persons, who stood hand in hand. The longest length of real telegraph line through which I have attempted to converse has been about 250 miles. On this occasion no difficulty was experienced so long as parallel lines were not in operation. Sunday was chosen as the day on which it was probable other circuits would be at rest. Conversation was carried on between myself, in New York, and Mr. Thomas A. Watson, in Boston, until the opening of bisiness upon the other wires. When this happened the vocal sounds were very much diminished, but still audible. It seemed, indeed, like talking through a storm. Conversation, though possible, could be carried on with difficulty, owing to the distracting nature of the interposing currents.

"I have had the opportunity of testing the telephone upon the artificial cable owned by Sir William Thomson. No difficulty was experienced in conversing through the equivalent of 120 miles of submarine cable. Vocal sounds were audible when the equivalent of the whole Atlantic cable was interposed between the two telephones, but the sounds were so faint that conversation could not be carried on. Songs that were sung into one telephone were readily recognised at the other end of the circuit, and the articulation of pre-arranged sentences was readily recognised. That the sounds were electrically produced was evident from the fact that they ceased when the circuit was broken and when the coils of the telephone were short circuited. No difference was observed between the pitch of the note which was transmitted through the artificial cable and the same note when transmitted directly through the air. The artificial cable experimented upon had four times the resistance of the Atlantic cable, and one-fourth its electrostatic capacity. I am informed by my friend, Mr. Preece, that conversation has been successfully carried on through a submarine cable, sixty miles in length, extending from Dartmouth to the Island of Guernsey, by means of hand telephones."

In a lecture on the 8th inst. at Glasgow, Prof. Bell, referring to the use of the telephone in mines, pointed out how the instrument might be of the greatest service in determining whether the ventilation of a mine was perfect or not; for by listening to the telephone, if the mine was in good order, a little sound could be heard every moment.

\section{AFRICAN EXPLORATION}

MR. STANLEY'S letter and the map in the Telegraph I of Monday enable us to realise somewhat more fully the nature and extent of the discoveries made by the 
intrepid traveller. Mr. Stanley is bent on calling the great river, so much of which he has explored, by the name of Livingstone. As a rule we think it a mistake to change native geographical names where these can be satisfactorily ascertained. In the case of the LualabaCongo, however, the river seems to have quite as many names as there are tribes or villages on its banks, and it would be a happy solution of the difficulty to confer upon it the most memorable name among African explorers. Mr. Stanley himself has taken great pains to obtain accurately the native names of tribes and places, and he animadverts with severity on geographers for crowding the map of Africa with names that probably correspond to nothing. For this they cannot be greatly blamed, neither need he be too hard on previous travellers for misunderstanding the significance of native words.

A glance at the map, notwithstanding that it is based to some extent on conjecture, shows at once the vast importance of Mr. Stanley's discovery. Great tributaries join the main river from both sides, and we are assured there are many more besides these shown on the map. For more than 800 miles of its course, above the Yellala Falls, the river looks more like a long winding lake than anything else, forming a magnificent channel for navigation. Above the upper cataract, again, about the equator, many other long reaches are capable of navigation, while the affluents will afford over 1,200 miles, and perhaps much more. Some idea of the increasing magnitude of the river below Nyangwe may be obtained from Stanley's statement that at Nyangwe the volume is 124,000 cubic feet per second, while Behm's calculation on the basis of Tuckey's trustworthy observations makes its volume at the mouth to be $1,800,000$ cubic feet per second. Poor Tuckey comes in for a share of Stanley's castigation, because, according to Stanley, the former mistook the number of stages of the Yellala Rapids; even if Tuckey was a little out in his counting, which we doubt, he will still be found to have been, all circumstances considered, an accurate observer. Many points, also, in connection with the map, show how true was Livingstone's geographical instinct, and how near the truth his inferences came from the information obtained from the Arabs and natives. Stanley is probably right in conjecturing that the Aruwimi, coming from the north-east, and joining the Livingstone a little north of the equator, is the Welle, and that the Ikelemba is the lower course of the Kasai. The water of the latter is of the colour of tea, and does not thoroughly mingle with the main stream until after I 30 miles below the confluence. The banks of the great river are thickly populated by what appear to be industrious people living in extensive and well laid out towns, and naturally jealous of intruders. The three most powerful tribes on the middle and lower rivers are the Wa-Mangala, the Warunga, and the Wyanzi.

The Livingstone, Mr. Stanley found, is subject to periodical rises mainly owing to the rains, and varying from eight to fifty feet. The entire length of the Livingstone Mir. Stanley calculates at 2,900 miles, and its basin at 860,000 square miles. The extreme sources of the Bemba Lake, from which the Luapula flows, are in $33^{\circ} \mathrm{E}$. long. Lake Bemba, or Bangweolo, Stanley states-and there appears to be good ground for the belief -is the residuum of an enormous lake that in very ancient times must have occupied an area of 500,000 square miles, "until by some great convulsion the western maritime mountain chain was riven asunder, and the Livingstone began to roar through the fracture." As to the "great convulsion" and the "fracture," geologists may be able to decide when they are in possession of full information as to $\mathrm{Mr}$. Stanley's observations. Nyangwe, Mr. Stanley informs us, is in $4^{\circ} 16^{\prime} \mathrm{S}$., and $26^{\circ} 5^{\prime} \mathrm{E}$.; but by an unaccountable mistake in another place he gives the latitude as $26^{\circ}$ $15^{\prime} 45^{\prime \prime}$, and that, too, while pointing out, in his peculiar way, a slight mistake in the position on Stanford's map of
1874. The position then was perfectly correct according to the data, and in the latest editions the position is exactly as Stanley gives it.

Mr. Stanley insists on the importance of the river as a commercial highway, the country traversed by it being abundantly rich in products that would find a ready market in Europe. Naturally, on Monday night, Africa was the burden of the president's address at the opening of the Geographical Society. Sir Rutherford Alcock insisted that it now remained with the merchant, aided if need be by Government, to open up Africa still further. Indeed the country is now being attacked by national and private expeditions on all sides, and if a basis for minute exploration were formed by trading stations under government sanction and regulation, along the Livingstone, our knowledge of the country would grow rapidly, and the benefits to commerce would be incalculable. Only, however, could the natives have fair play by governmental regulation of private enterprise. There is no danger of extinction for the native African, and it would be both prudent and just to protect him from the horrible cruelties at which Mr. Stanley hints in the conclusion of his letter.

It is worth noticing that in the map the Lukuga runs boldly from Lake Tanganyika and joins the Lualaba, and the source of the Alexandra Nile is brought to near $4^{\circ}$ south on the east side of the lake.

According to latest intelligence Mr. Stanley is at the Cape wanting to get his followers sent back to Zanzibar. In his letter in yesterday's Telegraph he gives an interesting account of his companion, Frank Pocock, of whom he speaks in the highest terms, and whose death is a real loss to African exploration.

The Daily Nezes Alexandria Correspondent writes (on the 5th) that Signori Gessi and Matteucci have just started from Cairo for Khartum, viâ Assouan, by the Nile, instead of taking the shorter route by the Red Sea to Massowa. They are provided with the newest and most improved scientific instruments, and having promised to keep up constant communication with the Geographical Society at Rome, interesting accourts of their movement and progress will be looked for.

\section{MODERN TORPEDO WARFARE}

TWO elements have contributed to make torpedo warfare what it is : electricity and the new explosive compounds. It is true that in the Whitehead or fish torpedo recourse is had only to the latter of these, but it is the sole material exception, and all the mischief effected by this branch of marine warfare has been, so far, the result of electric torpedoes. Both on the Danube and in the last American war, when no less than twenty-five ships were sunk by the Confederates, the electric torpedo has worked extensive injury, and it is no wonder therefore that a keen interest should be taken in all that pertains to so novel and destructive a method of killing and wounding.

We have called the torpedo a novel weapon, and the instruments that go by the name to-day undoubtedly are so. At the time of the Crimean war, we had to do with torpedoes of a kind; nay, even so far back as the beginning of the seventeenth century, floating charges, called petards, were employed, but these were of too insignificant a nature to merit attention. The "infernal machines" strewn in the Baltic by the Russians twenty years ago were small canisters of powder containing by way of igniting arrangement a mixture of chlorate of potash and sugar, together with a glass bulb with sulphuric acid; and the latter, escaping from its envelope when this was broken by a shock or collision, brought about an immediate explosion. These mechanical torpedoes had two disadvantages; the igniting arrangement was of such a character that it could be set in action just as well by friend as by foe, and the explosion of the gun- 